\title{
Terrorismo y contraterrorismo en Colombia ${ }^{\star}$
}

\author{
Terrorism and Counterterrorism in Colombia
}

\author{
Ariel Álvarez Rubio ${ }^{* *}$ \\ Universidad de Santiago de Chile, Santiago de Chile
}

Recibido: 13 de febrero de 2015. Aprobado: 15 de junio de 2015

\begin{abstract}
Resumen
El presente artículo da cuenta de un análisis referido al terrorismo y a las acciones contraterroristas evidenciadas en Colombia, con énfasis en el período comprendido entre el fin de la guerra fría y el año 2013. Este estudio abarca tanto la tipología emergente del terrorismo presente en Colombia, como también las políticas de Estado, establecidas para enfrentar, en el mismo lapso de tiempo, las amenazas impuestas por el terrorismo. Los antecedentes evaluados, permiten inferir el grado de responsabilidad histórica que le compete tanto a las Fuerzas Armadas Revolucionarias de Colombia - Ejército del Pueblo (FARC-EP) como al propio Estado, respecto del grave estado de violencia en que se encuentra sumida la sociedad colombiana.
\end{abstract}

Palabras claves: terrorismo, contraterrorismo, FARC-EP.

Este artículo es resultado de los avances de investigación de la tesis doctoral "La toma de rehenes como acto terrorista internacional. Un análisis integrado de los casos de Perú y Colombia”, Programa de Doctorado en Estudios Americanos mención Estudios Internacionales de la Universidad de Santiago de Chile (USACH).

** Oficial (Ret) de la Fuerza Aérea de Chile; Doctor en Estudios Americanos por la Universidad de Santiago de Chile; Asesor académico de la Academia Politécnica Aeronáutica de la Fuerza Aérea de Chile; Profesor Titular de la Academia de Guerra Aérea de la Fuerza Aérea de Chile; Asesor del Centro de Estudios Económicos y de Comercio de América Latina (CEECAL) del Instituto Universitario Tecnológico CHIHLEE, Taiwán, República de China (R.O.C). Correo electrónico: aalvarez@fach.mil.cl 


\begin{abstract}
This article reports on an analysis referred to terrorism and counterterrorism shares evidenced in Colombia, with emphasis on the period between the end of the Cold War and 2013. This analysis, based on a study covering both emerging typology of terrorism present in Colombia, as well as state policies established to address, in the same period, the threats posed by terrorism. The background evaluated to infer the degree of historical responsibility that falls upon both the FARC-EP and the State itself Forces, regarding the serious state of violence that is mired Colombian society.
\end{abstract}

Keywords: terrorism, counterterrorism, FARC-EP.

\title{
Introducción
}

Existen distintos puntos de vista respecto de la denominación de lo que ocurre en Colombia. De hecho se habla tanto de conflicto armado, como de conflicto armado interno y de lucha contra el terrorismo. El caso es que este país ha sufrido una escalada de violencia desde 1949 o incluso en fecha anterior y, la versión actual de violencia, se encuentra presente desde hace unos 40 años, por lo que sea cual sea la denominación de este tipo de conflicto, lo importante es reconocer el grave daño que esta lucha fratricida ha causado tanto a Colombia como a sus habitantes, sobre todo por el uso indiscriminado del terrorismo por parte de las FARC.

Al respecto, Juliana Castellanos Díaz (2013, p. 7), nos señala que:

Visualizar los costos económicos de este conflicto armado es una labor que permite dimensionar la crueldad del fenómeno y finiquitar la paradoja que divide al país en uno que invierte cantidades asombrosas en la guerra y otro que, en consecuencia cuenta, con recursos mínimos para asegurar la calidad de vida a sus ciudadanos a través del desarrollo equitativo.

Por otra parte, también asevera que "pese a la estabilidad económica que el país ostenta en los últimos años, el conflicto armado ha inhibido un avance de mayor envergadura y que, de no tenerse, Colombia sería un modelo a seguir" (2013, p.7). Como sea, 
la cuestión es compleja por tratarse de uno de los conflictos más viejos del mundo, que ha frustrado el desarrollo social, político y económico, sobre todo de las áreas rurales.

Los costos que ha producido el conflicto armado interno abarcan tópicos muy disímiles tales como: 1) destrucción de vidas humanas y de infraestructura; 2) disrupción de la vida normal (inseguridad en las vías y aumento en gastos de seguridad); 3) desviación de fondos para enfrentar el conflicto (inversión del Estado en material de guerra); 4) transferencia de las inversiones de privados hacia países más seguros; y 5) pérdida acumulada de crecimiento debido al stock acumulado de capital humano, físico y financiero (Castellanos, 2013, pp. 9-10).

Otro dato respecto a estos costos, nos señala que en Colombia se destinan del presupuesto general de la nación aproximadamente 22 billones de pesos anuales al sector de seguridad y defensa, lo que implica que en los últimos 10 años el conflicto armado le ha costado a Colombia, solo en ese frente, aproximadamente 220 billones de pesos.

En otro enfoque, el Grupo de Memoria Histórica-GMH ${ }^{1}$, ha emitido un informe donde señala que Colombia tiene una larga historia de violencia, pero también una renovada capacidad de resistencia a ella. Rompiendo todos los cánones de los países en conflicto, la confrontación armada en este país discurre en paralelo con una creciente confrontación de memorias y reclamos públicos de justicia y reparación. En este contexto, el GMH ha resaltado que "la memoria se afincó en Colombia no como una experiencia del posconflicto, sino como factor explícito de denuncia y afirmación de diferencias" (Grupo de Memoria Histórica, 2013, p. 13).

Al respecto, es necesario destacar que Colombia apenas comienza a esclarecer las dimensiones de su propia tragedia. El carácter invasivo de la violencia y su larga duración han actuado paradójicamente en detrimento del reconocimiento de las particularidades de sus actores y sus lógicas específicas, así como de sus víctimas. Durante décadas, las víctimas fueron ignoradas tras los discursos legitimadores de la guerra, bajo el descriptor

$1 \quad$ El Grupo de Memoria Histórica $(\mathrm{GMH})$ es un grupo de investigación perteneciente a la entonces denominada Comisión Nacional de Reparación y Reconciliación (CNRR) que tiene como objetivo elaborar y divulgar una narrativa sobre el conflicto armado en Colombia que identifique "las razones para el surgimiento y la evolución de los grupos armados ilegales” (Ley 975 de 2005), así como las distintas verdades y memorias de la violencia, con un enfoque diferenciado y una opción preferencial por las voces de las víctimas que han sido suprimidas o silenciadas. Además, el grupo formula propuestas de política pública que propicien el ejercicio efectivo de los derechos a la verdad, la justicia, la reparación y las garantías de no repetición (Nota del autor). 
peyorativo de 'daños colaterales'. Desde esta perspectiva, las víctimas fueron consideradas como un efecto residual de la guerra.

Por su parte, Daniel Pécaut (2001, p. 88) ha expresado que:

El conflicto armado interno en Colombia desbordó en su dinámica el enfrentamiento entre los actores armados. De hecho, de manera progresiva, especialmente desde mediados de la década de los 90, la población ha sido vinculada a los proyectos armados, no por consentimiento sino que por coerción, al punto que algunos analistas han definido esta dinámica como 'guerra contra la sociedad' o 'guerra por población interpuesta?

La violencia contra la población civil en el conflicto armado interno se ha distinguido por la sucesión cotidiana de eventos de pequeña escala tales como: 1) asesinatos selectivos; 2) desapariciones forzosas; 3 ) masacres con menos de seis víctimas; 4) secuestros; 5) violencia sexual; y 6) minas antipersonales. Todo esto dentro de una estrategia de guerra que deliberadamente apuesta por asegurar el control a nivel local, pero reduciendo la visibilidad de su accionar en el ámbito nacional.

En este conflicto, los actores armados se han valido tanto de la dosificación de la violencia como de la dosificación de la sevicia, esta última sobre todo como recurso para aterrorizar y someter a las poblaciones. En este sentido, se ha podido confirmar que entre 1958 y 2012 el conflicto armado ha ocasionado la muerte de por lo menos 220.000 personas, cifra que sobrepasa los cálculos hasta ahora sugeridos. Aparte de la enorme magnitud de muertos, se evidencia también un aterrador despliegue de sevicia por parte de los actores armados sobre la población civil. Esta ha sido una guerra sin límites en la que, más que las acciones entre combatientes, ha prevalecido la violencia desplegada sobre la población civil.

Según el GMH, en Colombia, el conflicto armado interno no tiene una modalidad de violencia distintiva. Los actores armados enfrentados en este conflicto han usado todas las modalidades de violencia. Todos han cometido crímenes de guerra y de lesa humanidad, siendo la población civil la principal víctima del conflicto. Si bien todos fundaron su estrategia en la violencia, no todos la han practicado con la misma intensidad ni con igual grado de crueldad ${ }^{2}$.

2 El GMH en su análisis ha destacado fundamentalmente tres categorías de actores armados: 1) los paramilitares; 2) las guerrillas; y 3) los propios agentes del Estado o integrantes de la Fuerza Pública (Nota del autor). 
El informe del GMH (2013, p. 13) destaca que:

En el caso de los paramilitares, son quienes ejecutaron en mayor medida masacres, asesinatos selectivos y desapariciones forzadas, e hicieron de la sevicia una práctica recurrente para incrementar su potencial de intimidación. Las guerrillas, por su parte han recurrido primordialmente a los secuestros, los asesinatos selectivos, y los atentados terroristas, además del reclutamiento forzado y el ataque a bienes civiles. Con respecto a la violencia ilegal de miembros de la Fuerza Pública, se ha podido establecer con base en testimonios y en sentencias judiciales el empleo de modalidades como detenciones arbitrarias, las torturas, los asesinatos selectivos y las desapariciones forzadas.

La probada participación de agentes estatales como perpetradores de crímenes, ha resultado particularmente inquietante para la sociedad, el Estado en su conjunto, y para ellos mismos, dado el grado particular de legalidad y responsabilidad que les compete. Además de su participación directa en la violación de derechos humanos, todos los casos documentados por el GMH registran con notable regularidad la connivencia y las omisiones de miembros de la Fuerza Pública, con acciones violatorias de los derechos humanos y alianzas con grupos poderosos que por métodos violentos defienden intereses económicos y políticos, o buscan el acceso a más tierra y/o recursos.

La complejidad del conflicto armado interno en Colombia, se evidencia a través de la variedad y alcance de las distintas modalidades de violencia presentes en dicho conflicto, y entre las cuales se pueden mencionar las siguientes: 1) la convergencia entre el narcotráfico y los grupos militares; 2) las alianzas del crimen organizado con la Fuerza Pública; 3) la convergencia entre el proyecto paramilitar y los poderes local y regional asediados por la guerrilla; 4) la persecución y el exterminio de los líderes, movimientos y partidos de izquierda; 5) la disputa entre las FARC y los paramilitares por el control territorial; 6) la disputa entre distintos actores por el control de la economía regional de la coca; 7) el desplazamiento forzado y el destierro masivo de los habitantes; 8) la siembra de minas antipersonales; 9) el secuestro y la violencia sexual; 10) la sevicia y la tortura; y 11) la amenaza y las acciones bélicas, entre otras.

Ahora bien, como motor del origen y la perduración del conflicto, se encuentra presente la apropiación, el uso y la tenencia de la tierra, con lo cual se puede inferir que existe una convergencia gradual entre la guerra y el problema agrario. A estos viejos problemas vinculados con la tierra ahora se han sumado otros nuevos, tales como: 1) el narcotráfico; 2) la explotación minera y energética; 3) los modelos agroindustriales; y 4) 
las alianzas criminales entre paramilitares, políticos, servidores públicos, élites locales económicas y empresariales, y narcotraficantes.

Según el GMH, ver la violencia desde la perspectiva de la tierra y los territorios ha revelado otro rasgo distintivo de su historia: "la guerra se ha librado mayoritariamente en el campo colombiano, en los caseríos, veredas y municipios, lejos y apartados del país central o de las grandes ciudades" (GMH, 2013, p. 22).

De este modo, el conflicto se ha transformado en una guerra de la que se tiene noticia a través de los medios de comunicación. Una guerra que sufren otros y que permite a miles de personas vivir en la ilusión de que el país goza de democracia plena y prosperidad, a la vez que les impide entender la suma importancia de cada decisión, afirmación o negociación política para quienes la sufren. Un pacto de un cese al fuego, representa para los campesinos la diferencia entre quedarse o huir, entre vivir o morir, en tanto que para quienes viven lejos de los lugares de enfrentamiento aquello no significa nada.

En este complejo escenario, se puede interpretar la guerra interna como un asunto de precariedad y debilidad de la democracia. La guerra ha terminado constituyéndose como un recurso destinado a impedir la democracia y la violencia se ha transformado en el medio más recurrido para acallar a críticos y opositores, dificultando la denuncia y evitando así los justos reclamos y transformaciones que amerita la sociedad colombiana.

En este mismo escenario, existen también contradicciones y limitaciones por parte de la justicia para afrontar el conflicto armado. La relativa independencia y credibilidad de las instituciones del Estado, en muchas ocasiones ha terminado por ser configurada tanto por cuenta de actores armados específicos o por cuenta de la dinámica compleja del conflicto armado colombiano, lo que ha inducido a la creación de diseños institucionales para enfrentar lo que en determinado momento ha sido considerado como la más grave amenaza, pero que en muchas ocasiones no ha sido otra cosa que una vinculación del sistema de justicia a determinadas estrategias armadas. 


\section{Tipología del terrorismo emergente en Colombia}

\section{Una violencia difícil de medir}

La investigación realizada por el GMH demuestra empíricamente que el conflicto armado colombiano es uno de los más sangrientos de la historia contemporánea de América Latina. Este conflicto ha causado la muerte de aproximadamente 220.000 personas entre el 1 de enero de 1958 y el 31 de diciembre de 2012.

La violencia instalada durante muchas décadas en Colombia no es simplemente una suma de hechos, víctimas o actores armados, sino que es producto de 'acciones intencionales' que se inscriben mayoritariamente en 'estrategias políticas y militares', y se asientan sobre complejas 'alianzas y dinámicas sociales'.

Al 31 de marzo de 2013 el Registro Único de Víctimas-RUV ${ }^{3}$, reportó que 166.069 civiles fueron víctimas fatales del conflicto armado desde 1985 hasta esa fecha. Sin embargo, este balance es parcial debido a que el marco legal solo reconoce a las víctimas a partir del 1 de enero de 1985, lo que excluye a 11.238 víctimas documentadas en la base de datos del GMH entre 1958 y 1984. Asimismo, es importante señalar que en el RUV no están incluidos los combatientes muertos en las acciones bélicas. De acuerdo con la investigación del GMH, entre 1958 y 2012, murieron 40.787 combatientes. Es así como al integrar estas cifras, es posible afirmar que el conflicto armado colombiano ha provocado aproximadamente 220.000 muertos. De estas muertes el $81,5 \%$ corresponde a civiles y el $18,5 \%$ a combatientes; es decir que aproximadamente ocho de cada 10 muertos han sido civiles, y que, por lo tanto, son ellos los más afectados por la violencia.

Al contrastar estos datos en relación con otros tipos de violencia que afectan a la sociedad colombiana, se puede argumentar que una de cada tres muertes violentas que se producen en Colombia es producto del conflicto armado interno. Otro dato importante es que no existe asimetría entre el número de muertos civiles y de muertos combatientes, ya que se ha comprobado que la población civil ha resultado más afectada, ya que por cada combatiente caído han muerto cuatro civiles.

3 El Registro Único de Víctimas-RUV fue creado a partir del artículo 154 de la Ley 1.448 del 2011 para garantizar la atención y reparación efectiva de las víctimas (Nota del autor). 
Por otra parte, estudios de notable esfuerzo han logrado estimar que tres de cada cuatro homicidios han quedado fuera de las estadísticas. En efecto, el contexto de la violencia generalizada en el que discurre el conflicto es aprovechado por los actores armados legales e ilegales para hacer invisibles sus acciones y confundirlas con hechos violentos perpetrados por otros. Los victimarios recurren a sicarios y a prácticas de violencia como las desapariciones forzadas y los asesinatos selectivos. De esta manera, logran dificultar el esclarecimiento del crimen y difuminan su resonancia entre las múltiples modalidades $\mathrm{y}$ tipos de violencia.

La letalidad de la violencia del conflicto armado no ha sido homogénea ni constante. De una tendencia decreciente entre 1958 y 1964, marcada por la transición de la violencia bipartidista a la subversión, se pasó a una violencia baja y estable entre 1965 y 1981. Esta violencia estuvo marcada por la irrupción de las guerrillas y su confrontación con el Estado. Posteriormente, entre 1982 y 1995, continuó una tendencia creciente marcada por la expansión de las guerrillas, la irrupción de los grupos militares, la propagación del narcotráfico, las reformas democráticas y la crisis del Estado. Seguidamente se dio una tendencia explosiva entre 1996 y 2002, en la que el conflicto armado alcanzó su nivel más crítico como consecuencia del fortalecimiento militar de las guerrillas, la expansión nacional de los grupos militares, la crisis del Estado, la crisis económica, la reconfiguración del narcotráfico y su reacomodamiento dentro de las coordenadas del conflicto armado. Esta tendencia fue sucedida por una etapa decreciente que va desde el 2003 hasta hoy, y ha estado marcada por la recuperación de la iniciativa militar del Estado, el repliegue de la guerrilla y la desmovilización parcial de los grupos paramilitares. Este período, sin embargo, plantea nuevas amenazas por el reacomodamiento militar de las guerrillas, el rearme paramilitar y el desgaste de la prolongación de la ofensiva militar del Estado, que no ha podido dar fin al conflicto.

Por otra parte, la violencia del conflicto armado tiene una dimensión no letal que acarrea consecuencias igualmente graves. Al 31 de marzo de 2013, el RUV reportó 25.007 desaparecidos, 1.754 víctimas de violencia sexual, 6.421 niños, niñas y adolescentes reclutados por grupos armados, y 4.744 .046 personas desplazadas. El GMH también reporta 27.023 secuestros asociados con el conflicto armado entre 1970 y 2010, mientras que el Programa Presidencial de Atención Integral contra Minas Antipersonal-PAIMA reporta 10.189 víctimas de minas antipersonales entre 1982 y 2012. 


\section{Estudio de las FARC}

\section{Generalidades}

En relación a la evolución de la violencia en Colombia y su relación directa con el surgimiento de movimientos guerrilleros, Leslie Bethell (2002, p. 202), ha señalado que:

Décadas de violencia partidista han permitido el surgimiento en Colombia de numerosos movimientos guerrilleros, los cuales ya sea en apoyo como en oposición al gobierno de turno, han impuesto la violencia como herramienta útil para sus respectivos intereses. Revisando brevemente la historia a partir de la década de los años 50, se destaca el golpe de Estado en 1953, producto del cual asume el poder el General Gustavo Rojas Pinilla. En dicha oportunidad, el General Rojas establece una amnistía y trata de acercarse a los líderes guerrilleros para alcanzar la paz. Sin embargo, varios grupos armados deciden continuar su lucha en la clandestinidad, donde algunos de estos grupos armados llegan incluso a establecer en sus áreas de operación, una suerte de "zonas independientes", en cuyos perímetros se imponen una "custodia armada" en tanto realizan incursiones armadas hacia las zonas aledañas.

Posterior a la salida del poder de Rojas, se instaura una Junta Militar de transición y, en estas circunstancias, los líderes de los partidos Liberal y Conservador acuerdan alternar el poder mediante un Sistema denominado Frente Nacional, destinado a concluir con las diferencias entre ambos partidos y, evitar así, que continúe la violencia desatada en años anteriores. Durante el gobierno de Guillermo León Valencia, segundo Presidente del Frente Nacional y, ante el aumento de la existencia de "zonas independientes" controladas por grupos guerrilleros armados, se decide emplear al Ejército para someter dichos lugares y restablecer la autoridad.

Una de estas zonas, ubicada en Marquetalia, no solamente logra sobrevivir a las acciones del Ejército, sino que sus líderes, tanto de tendencia liberal como comunista, integran a sus fuerzas a dirigentes estudiantiles, dando origen a las Fuerzas Armadas Revolucionarias de Colombia (FARC), quienes aparte de sus asentamientos en Marquetalia, crean zonas similares en El Pato (Caquetá), Río Chiquito (Cauca), Guayabero y el sudoeste de Tolima.

Por su parte, también en relación a la evolución de la violencia en Colombia, José María Benegas (2004, p. 210) señala lo siguiente: 
Las FARC surgieron en 1964 como una organización guerrillera ligada a la lucha de los campesinos colombianos sin tierra y al Partido Comunista Colombiano. Su nacimiento se vincula más concretamente a la represión que sufrieron los campesinos liberales amnistiados en una población al sur de Tolima (Marquetalia), donde llegaron a proclamar una República Independiente. La ideología de las FARC es marxista-leninista, con influencia revolucionaria cubana. También tiene cierta influencia del pensamiento del libertador Simón Bolívar, encuadrándose en el movimiento bolivariano. En la actualidad, las FARC son el grupo armado no estatal más activo, con mayor cantidad de efectivos (cerca de los 8.000, según las fuentes) y mejor equipado de Colombia. Sus antecedentes históricos proceden de la época conocida como La Violencia (19481958), guerra civil que enfrentó a los partidos tradicionales, tras el asesinato del líder populista liberal Jorge Eliécer Gaitán. El levantamiento popular en Bogotá, que luego se extendió al resto del país, fue reprimido con virulencia. En este conflicto civil murieron más de 200.000 personas.

Reconociendo el papel clave que revisten las FARC a continuación veremos un estudio de las mismas basado en tres variables principales que serán detalladas con mayor profundidad.

\section{Breve síntesis histórica de la evolución de las FARC}

En la actualidad, las FARC son consideradas como una agrupación terrorista por parte de 33 Estados y otros tantos organismos internacionales, entre los cuales se cuenta a Colombia, Perú, Estados Unidos, Canadá y Nueva Zelanda ${ }^{4}$.

La Unión Europea (UE), como parte de su respuesta contra el terrorismo tras los atentados del 11 de septiembre de 2001, en diciembre de ese mismo año estableció una lista de personas, grupos y entidades implicados en actos terroristas y sujetos a medidas restrictivas. Estas medidas, fijadas en la posición común 2001/931/PESC, son medidas adicionales adoptadas con el fin de aplicar la resolución 1373 (2001) del Consejo de Seguridad de las Naciones Unidas. En esta lista se incluye a personas y grupos terroristas

4 En el caso de Estados Unidos, de acuerdo con el artículo 219 de la Ley de Inmigración y Nacionalidad (INA) de ese país, el Departamento de Estado ha encasillado a las FARC dentro de la categoría de "Foreign Terrorist Organizations (FTOs) desde el 8 de octubre de 1997. Con esta designación, EE.UU. pretende constituir un medio eficaz para restringir el apoyo a las actividades terroristas y presionar a esos grupos para salir de dicha actividad. Cfr. "Foreign Terrorist Organizations (FTOs)" (Secretaría de Estado de Estados Unidos, 2015). 
activos, tanto dentro como fuera de la UE y se revisa periódicamente al menos cada seis meses. En este listado, se incluye a las FARC como una organización terrorista activa y como tal se han establecido medidas relacionadas con la congelación de capitales y activos financieros y medidas relacionadas con la cooperación policial y judicial en contra de la citada organización (Consejo Europeo y Consejo de la Unión Europea, 2015).

En un contexto similar, tanto las Naciones Unidas como Amnistía Internacional y Human Rights Watch, entre otras organizaciones, han reclamado a las FARC por las sistemáticas violaciones al Derecho Internacional Humanitario (DIH) y al Protocolo II adicional a los Convenios de Ginebra. Entre otras trasgresiones, las FARC han sido acusadas reiteradamente por reclutamiento de menores, actos de violencia sexual contra mujeres y niñas, violaciones y torturas, desapariciones forzadas, secuestro de civiles, trato inhumano a rehenes, desplazamiento forzado y narcotráfico. Todos estos antecedentes, a juicio del autor, vienen a justificar su designación como organización que ha hecho uso sistemático del terrorismo como herramienta estratégica violenta para el logro de sus objetivos.

Para realizar un estudio sobre las FARC, resulta necesario realizar una síntesis de la evolución que ha tenido esta organización, y para tal efecto es pertinente revisar tres ejes principales: 1) analizar las representaciones de las FARC sobre sí mismas y las que la sociedad ha elaborado de esa guerrilla; 2) analizar el desarrollo militar en un sentido amplio (estrategias, métodos de guerra, recursos y dominios territoriales); y 3) analizar las relaciones que este grupo insurgente ha tenido con la población civil.

Lo anterior, nos conduce a efectuar una periodización histórica que se ajuste a las tres variables mencionadas, lo que nos permitirá identificar una serie de cambios que se han producido en la sociedad colombiana y por otra parte, las diferentes transformaciones que ha experimentado la guerrilla a lo largo del conflicto interno colombiano. Para tal efecto, se utiliza una periodización histórica que ha sido propuesta por el Centro Nacional de Memoria Histórica de Colombia (CNMH).

\section{Primera Fase (1949-1978)}

El CNMH (2014, pp. 17-18) establece una primera fase comprendida entre 1949 y 1978 que se encuentra enmarcada dentro de dos acontecimientos: 1) el surgimiento de las guerrillas comunistas tras el asesinato de Jorge Eliécer Gaitán y el comienzo de la violencia bipartidista; y 2) la VI Conferencia de las FARC en 1978, ocasión en que este grupo insurgente se propuso convertirse en una guerrilla nacional, en un Ejército Revolucionario, y cuando definió que su proyecto era la toma del poder. 
Si bien esta Fase contempla el surgimiento de las FARC en 1964, y le da la importancia que tiene para la historia de esa organización, subraya que hubo significativas prolongaciones entre las guerrillas comunistas y las FARC.

En los primeros años de esa organización armada continuó operando la fuerte subordinación al Partido Comunista; la falta de claridad sobre sus fines estratégicos; la persistencia en ciertas zonas; la continuidad de algunos de sus métodos de guerra y de un discurso político construido sobre el conflicto agrario y la deuda histórica que habría dejado la violencia partidista. En esta fase se visualiza una guerrilla marginal, silenciosa, poco combativa, que mezcla sus antiguos procedimientos con nuevas formas de atracción y sujeción social en sus relaciones con los campesinos, que aboga por una presencia estatal en sus zonas de influencia y que socialmente es percibida como una guerrilla nacida de la violencia partidista y de un conflicto social no resuelto por el Estado.

A modo de conclusión de esta primera fase, se puede señalar que las FARC tuvieron inicialmente un carácter casi exclusivamente rural y muy limitado a acciones en pequeñas zonas de influencia. Sin embargo, luego comienzan a crecer lentamente, llegando a contar con unos 3.000 efectivos a finales de la década de 1970.

\section{Segunda Fase (1978-1991)}

Esta segunda fase, según el CNMH (2014, p. 18), se haya delimitada, de un lado, por la crisis política de finales de los años 70, generada por el auge de la guerrilla particularmente urbana y las protestas sociales. Esta crisis intentó ser superada por la vía militar con la expedición del llamado Estatuto de seguridad. De otro lado, se conecta con otra grave crisis, la de finales de los años 80, derivada del ascenso del narcotráfico, de la insurgencia y del paramilitarismo, que desemboca en la Asamblea Constituyente y en la promulgación de una nueva Constitución.

Esta es una fase de transición para las FARC. La guerrilla se reformula a sí misma, y obtiene importantes resultados: 1) conquista nuevos territorios ofreciendo en las zonas rurales diversas formas de intercambio a partir de las peculiaridades regionales; 2) se dota de un plan estratégico para la toma del poder, que transforma la guerra y la historia reciente del país; 3) expide normativas internas; 4) continúa combinando la guerra y la 
política al crear la Unión Patriótica ${ }^{5}$ 5) construye las bases de su retaguardia nacional; y 6) recibe el primer impacto de la economía del narcotráfico.

Este período se cierra con el exterminio de la Unión Patriótica (U.P ${ }^{6}$, tras lo cual las FARC toman la decisión de hacer la guerra hasta la victoria final, distanciándose en forma definitiva de la negociación y del proceso constituyente de 1991.

A modo de conclusión, se puede destacar que es en esta década, donde las FARC establecen un nexo con el narcotráfico, dada la condición de actividad creciente que empieza a adoptar este fenómeno. De esta forma, se implanta gradualmente, el cobro de impuestos a productores y a narcotraficantes como fuente de financiamiento. Por otra parte, en 1984, durante el gobierno de Belisario Betancourt, se establecen acuerdos de cese del fuego con las FARC e incluso éstas últimas logran integrarse a los movimientos políticos luego de crear la Unión Patriótica.

\section{Tercera Fase (1991-2008)}

En la tercera fase, el CNMH (2014, pp. 18-19) señala que se expresa el desarrollo y el declive del plan estratégico, también denominado Campaña para la Nueva Colombia, con la que las FARC pretendieron ocupar la capital del país. En esta fase, la guerrilla se comprometió con la guerra, desarrolló la ocupación territorial y la ofensiva militar, incluyendo la negociación como estrategia política para desembocar en la acentuación de las acciones militares o para concluir en la creación de una nueva república en sus

5 La Unión Patriótica (UP) surgió como un movimiento político amplio, democrático y de oposición a los partidos tradicionales. La UP, a finales de 1985, planteó un programa democrático coincidente en varios de sus puntos con las propuestas de las FARC: eliminación del monopolio bipartidista, elección popular de alcaldes y gobernadores, abolición de las normas constitucionales que sustentaban la declaración de estado de sitio, vigencia del principio de soberanía popular, la desmilitarización y eliminación de los grupos paramilitares, la nacionalización de la banca, el no pago de la deuda externa, el respeto por los derechos de las comunidades indígenas, el impulso de una política internacional independiente y ajena a la influencia de Estados Unidos Desde su surgimiento, la UP fue vista por unos como una posibilidad de lograr que la guerrilla pudiera incorporarse a la vida civil, y por otros como una simple "fachada” o "apéndice de la subversión". La segunda consideración convirtió a la UP en blanco de todo tipo ataques, al punto que en el primer año de existencia legal registrara 300 militantes asesinados (CNMH, 2014, pp. 126-132).

$6 \quad$ En abril de 1987, la UP se desligó de las FARC condenando sus métodos de secuestro y extorsión. Esto provocó fuertes discrepancias con los guerrilleros y la división al interior del PC, que se empecinaron por buscar el rescate ideológico de la UP. El 22 de marzo de 1990, el líder de la UP Bernardo Jaramillo fue asesinado y aquello contribuyó en buena medida para impedir que este movimiento político continuara su proceso de consolidación. Las FARC persistieron en apoyar a la UP en las campañas electorales de 1989 ( CNMH, 2014, pp. 135-137). 
zonas de retaguardia nacional e incluso en la posibilidad del reconocimiento del Estado de beligerancia.

Ante esto, el Estado respondió con unas Fuerzas Armadas renovadas gracias al apoyo de Estados Unidos, aplicando el Plan Colombia y desarrollando diversas campañas como el Plan Patriota y el Plan Consolidación que terminaron forzando a la guerrilla a un repliegue militar. El accionar de las Fuerzas Armadas también implicó que las FARC perdieran gran parte de su control territorial, que se confinaran en zonas despobladas y selváticas, que se desmantelaran muchos de sus frentes, que varios de sus principales comandantes murieran y que su dotación de fuerza disminuyera como resultado de múltiples deserciones".

Por otra parte, es en esta misma fase donde las FARC experimentan también un notable desprestigio a causa de los métodos de guerra utilizados, tales como el secuestro y los atentados explosivos (utilización de cilindros bomba y minas antipersonal), y por la deslegitimación que proyecta el manejo de recursos provenientes del narcotráfico, entre otros.

Según Bethell (2002, p. 256), durante la década de 1990:

Las tentativas de negociación entre las FARC y el gobierno, sufren sucesivos rompimientos de los acuerdos de cese del fuego y, a inicios de esta misma década, las FARC alcanzan los 10.000 guerrilleros, organizados en 70 Frentes distribuidos a lo largo de todo el país.

En 1998, el gobierno de Andrés Pastrana establece nuevos acuerdos con las FARC, creándose la zona de distensión, que consistía en una zona desmilitarizada de $40.000 \mathrm{~km}^{2}$ comprendida entre los municipios de Mesetas, La Uribe, La Macarena, Villahermosa y San Vicente del Caguán. La idea del gobierno con este acuerdo, era llevar a cabo un proceso de paz con los guerrilleros.

Sin embargo, con esto las FARC empezaron a tener presencia urbana, implantando incluso una administración armada contra la población civil, pese a que esto no estaba contemplado en acuerdo alguno. Este proceso de paz duró hasta el 2002 y, pese a ciertos avances teóricos y documentales, las tensiones y polémicas alrededor de la negociación no permitieron que se lograran resultados positivos. De hecho, ese mismo año las FARC secuestran un avión comercial, liberan a todos los pasajeros pero mantienen secuestrado al senador Jorge Gechem. 
$\mathrm{Al}$ incrementar su dominio territorial, las FARC ganaron poder negociador y utilizaron los atentados para desestabilizar, con el objetivo de forzar al Estado a negociar un acuerdo de paz. De hecho, en los años 90, el área de la frontera agrícola se movió en las cercanías de la selva amazónica (departamentos de Caquetá, Putumayo y Meta). Este movimiento se corresponde al incremento de las actividades ligadas al cultivo de la coca. Un cambio de estrategia en la financiación de la guerrilla, que cobró impuestos a los productores de coca en la zona controlada por ella, favoreció que estos productores comprasen tierras en otras zonas para poder compensar con más producción esos pagos. Los campesinos que huían de la violencia de los terratenientes, escapan hoy de los capos del narcotráfico que invierten sus recursos en tierras.

Respecto a la evolución de las FARC en esta tercera fase resulta interesante observar los análisis que realiza Alfredo Rangel, quien destaca que en sus comienzos, las FARC se organizaron como un modelo típico de guerrilla, a semejanza de otros grupos insurgentes latinoamericanos surgidos a partir de la década de los años 50. Sin embargo, en 1982, en la VII Conferencia Nacional de Guerrilleros, se decidió la transformación de esa organización guerrillera en un ejército pasando a denominarse FARC-EP (Fuerzas Armadas Revolucionarias de Colombia - Ejército del Pueblo), y por lo tanto, a partir de ese momento, se constituyeron como un ejército jerarquizado con 60 frentes orientados hacia las principales ciudades del país.

En relación a su manera de operar, Alfredo Rangel (1998, p. 250) señala lo siguiente:

En la década de los años 90, las FARC se fijaron como objetivo alcanzar el poder no tanto en el ámbito nacional sino local. De esta forma, se abocaron a acumular poder en los municipios en un contexto más que nada económico, involucrándose en actividades afines con dicho objetivo y logrando así expandirse en varios espacios sociales del país. A pesar de la importancia creciente de las estrategias y de los intereses económicos en el desarrollo del conflicto, las FARC no pueden ser consideradas como delincuentes comunes. Las FARC son también actores políticos, ante todo locales, que utilizan sus recursos económicos para incrementar su radio de acción. Si bien es cierto, se puede suponer que las guerrillas han perdido algo de su ideología a lo largo de los años, todavía tienen ideales y discurso político. Además, son poderes políticos de facto, ya que controlan territorios, poblaciones y se insertan en la vida política de numerosas localidades por medio de la coerción (amenazan a los agentes del Estado, perturban las elecciones, etc.). Es así como lo político ha perdido su dimensión ideológica para volverse más pragmático en la medida en que está estrechamente relacionado con la gestión cotidiana de los municipios. 
Otro aspecto interesante que distingue Rangel en la estrategia de las FARC dice relación con el tiempo de la guerra. Por ello, para explicar la prolongación del conflicto es necesario resaltar que los recursos económicos han permitido a los actores armados sostener un esfuerzo prolongado de guerra, es decir ganar el tiempo requerido. Con el paso de los años, las FARC fueron acumulando fuerzas y por lo tanto el tiempo se transformó en un elemento rentable para la guerrilla ${ }^{7}$.

En un contexto similar, Rangel destaca que como parte de su estrategia, la guerrilla no persigue la derrota brutal del enemigo sino su agotamiento progresivo. Es decir, las FARC han buscado librar una guerra de desgaste, que es a la vez política, económica, militar y moral, y en la cual se evitan los enfrentamientos directos con el propósito de economizar fuerzas.

Como consecuencia de lo anterior, Rangel identifica la existencia de una guerra limitada en la estrategia de las FARC, ya que no se evidencian combates directos entre los actores en conflicto. Sin embargo, por otra parte también existe una gran movilización de recursos, ya que el conflicto se desarrolla en distintos campos (político, militar, económico, etc.) y, por lo tanto, ello se podría asociar con una guerra total.

De esta forma, surge la interrogante de hasta qué punto se puede hablar de guerra limitada cuando es la población civil quien se ve más afectada por una violencia indiscriminada. Todo lo anterior, nos permite identificar la situación en Colombia como altamente compleja.

Refiriéndose a esta evolución de las FARC, tanto de métodos como de objetivos, José María Benegas (2004, p. 211) agrega que:

La evolución de las FARC la ha llevado a utilizar cada vez más el terror como medio de presión al gobierno colombiano para lograr sus objetivos. Estos objetivos mezclan las exigencias de cambios en la propiedad de la tierra con toda una serie de reformas sociales y políticas que acaben con el actual sistema e instauren un régimen socialista y revolucionario. Un sistema político dominado por oligarcas, que consideran represivo y no representativo, es la justificación para la utilización de la lucha armada como único medio para imponer sus demandas. Los campesinos desplazados y la impuni-

$7 \mathrm{Al}$ respecto, es pertinente señalar que posteriormente el tiempo dejó de ser un elemento rentable para las FARC, debido a que las fuerzas militares colombianas, apoyadas por Estados Unidos, tomaron la iniciativa en el terreno militar aplicando el Plan Colombia y desarrollando diversas campañas tales como el Plan Patriota y el Plan Consolidación (Nota del autor). 
dad con la que el ejército y los grupos paramilitares actuaron contra la población de esas zonas, así como la tradicional situación de penuria económica y de dejación de las obligaciones del Estado en cuanto a la mejora de las condiciones de vida de esas poblaciones, justificarían el apoyo que estas áreas habrían dispensado a las FARC-EP, que a su vez habrían perdido debido a las matanzas indiscriminadas, a los secuestros y toma de rehenes, y a la expulsión masiva de los campesinos a conveniencia de los grupos armados.

En su búsqueda de recursos las FARC no han dudado en acudir a prácticas de extorsión, secuestro, toma de rehenes e intimidación física. De hecho, han sido numerosos los casos de secuestros y toma de rehenes de miembros de familias adineradas de Colombia con el objetivo de conseguir un rescate. También se ha especulado con la posibilidad de que hayan recibido dinero de Cuba, especialmente en la década de los 60 . En los últimos años, la vinculación de las FARC con el narcotráfico y los carteles, ha sido fundamental en la argumentación del gobierno estadounidense de la necesidad de acabar con el cultivo de la coca para terminar también con las acciones terroristas de las FARC.

Para Alfredo Rangel (1998, p. 353), las mayores críticas a las políticas de Estado con respecto al conflicto en Colombia durante el período 1991-2008, se relacionan con el hecho de que:

Frente al fenómeno de la insurgencia, el Estado ha tenido las posturas más disímiles, que se corresponden casi totalmente con los cambios de gobierno que se realizan cada cuatro años, sin que se advierta un hilo conductor, ni claridad de propósitos a largo plazo. El Estado no ha concitado el apoyo nacional hacia la lucha contrainsurgente, que durante mucho tiempo ha sido subestimada o cuya naturaleza no se ha comprendido a cabalidad. Como resultado de lo anterior, es que no se han logrado unificar los esfuerzos de manera permanente, ni siquiera dentro del mismo Estado o, la nación entera. Esta situación propició durante muchos años el mantenimiento de unas fuerzas militares muy poco adecuadas para contener y controlar una insurgencia que se desbordaba sin freno a lo largo de todo el territorio nacional.

8 De hecho, el llamado Plan Colombia, impulsado por el gobierno de Andrés Pastrana y el de Bill Clinton, estableció ayuda militar al gobierno colombiano, con el propósito declarado de contribuir al desarrollo de Colombia a través de la lucha contra el narcotráfico. Las cifras de la ayuda militar a Colombia están alrededor de los USD \$ 1.200 millones al año (Nota del autor). 


\section{Cuarta Fase (2008-2013)}

Según el CNMH (2014, pp. 19-20), con el paso del tiempo, las FARC han pasado de ser una poderosa fuerza de 18.000 combatientes capaces de atacar ciudades, y controlar grandes territorios del país a terminar siendo acorralados en las montañas y selvas, por una política de seguridad contrainsurgente liderada del gobierno liderado por Álvaro Uribe (2002-2010) y apoyada por Estados Unidos.

Este es el nuevo escenario, que caracteriza el actual período de evolución histórica de las FARC, que se inicia con el Plan Renacer formulado por Alfonso Cano a su llegada a la comandancia de la guerrilla y cierra con los primeros acercamientos de paz con el presidente Juan Manuel Santos y la hoja de ruta para la paz, integrada por cinco puntos.

En esta fase, la guerrilla reconoce el impacto del Plan Patriota ejecutado con ímpetu durante el primer gobierno de Álvaro Uribe Vélez y, en consecuencia, define la estrategia para su recuperación política y militar. Lo anterior, viene a demostrar que la guerrilla se ha podido acomodar a las nuevas condiciones del conflicto, apelando con relativo éxito a una guerra de resistencia o de sobrevivencia.

Para lograr aquello, la guerrilla ha seguido defendiendo algunas de sus zonas históricas, al mismo tiempo que ha tratado de incrementar sus combatientes. En la actualidad mantiene aún algunos de sus corredores estratégicos y ha continuado estableciendo alianzas económicas con bandas criminales. Por otra parte, ha continuado adoptando una estrategia de resguardo, mediante el uso de campos minados y empleo de armamento en ataques a distancia, tales como el uso de granadas de mortero, empleo de francotiradores y detonación de carros bomba.

Esta adaptación de las FARC a la ofensiva de la Fuerza Pública y el cuestionamiento al cada vez más lejano principio del fin de la subversión, ha llevado al Estado a rediseñar su estrategia militar mediante la aplicación del Plan Espada de Honor y a formular, contra todos los pronósticos, la posibilidad de buscar una salida negociada al conflicto.

Respecto de esta cuarta fase, se puede concluir que sólo el tiempo podrá dilucidar si los combatientes han logrado suficiente madurez política para apostar por la paz, evitando así nuevas confrontaciones armadas. En todo caso, la actual negociación se ha convertido en una ventana de oportunidades para generar transformaciones políticas y sociales que pueden profundizar la democracia en Colombia. 


\section{Análisis de variables o ejes principales de estudio de las FARC}

En relación a las variables o ejes principales definidos para el estudio de las FARC (imaginario de la memoria y el discurso, desarrollo militar y relaciones con la población civil), se puede argumentar lo siguiente:

\section{Imaginario de la memoria y el discurso de las FARC}

Respecto del imaginario de la memoria y del discurso de las FARC, la elaboración guerrillera de imágenes y argumentos que justifican la rebelión ha sido permanente, y han apuntado a presentar a las FARC como víctimas del Estado, que ante las agresiones emprendidas en su contra por parte de paramilitares y agentes del Estado, han tenido que actuar con una violencia obligada defensiva o de respuesta de la guerrilla contra el Estado, lo que se ha traducido también en la imagen de una insurgencia víctima de la fuerza abusiva o excesiva del mismo.

Este formato interpretativo tendió a desvanecerse cuando las FARC pasaron a convertirse en un ejército organizado, relativamente bien armado y ofensivo. En esas condiciones, la violencia esgrimida por las FARC comienza a ser vista como una violencia agresora, y sobre todo, sin excusa.

Al agotarse los argumentos e imágenes de las FARC que avalaban una violencia de respuesta, la sociedad colombiana se puso de lado de los actores legales e ilegales que repelían dicha agresión, y de esta forma la corriente de opinión a favor de la guerra empezó a superar a aquella que rechazaba la guerra y toda forma de violencia.

De esta forma, la violencia de respuesta, paso a ser socialmente compartida, justificada y aceptada para quienes combatían a la guerrilla, incluso por fuera del marco de la legalidad. 


\section{Desarrollo militar de las FARC}

En cuanto al eje de estudio relativo a la guerra, se puede resaltar la persistencia de ciertos modelos e ideas fijas que explican el accionar de las FARC. En este contexto, un primer aspecto relevante es el hecho de que las FARC han militarizado permanentemente la política, pues esta es considerada como un medio para hacer más eficaz la guerra.

En las FARC, la guerra y la política han sido indisolubles y siempre han fluido en la misma dirección. Si se revisan los eventuales caminos legales (la relación con el Partido Comunista, los lazos con organizaciones sociales y comunitarias, la creación de la Unión Patriótica y actividad difusa de los movimientos políticos clandestinos) o de los procesos de negociación, el cálculo siempre ha sido el mismo: impulsar el ideario revolucionario sumando conciencias y voluntades para hacer de la guerra una actividad socialmente compartida o realmente popular.

En 1982, con ocasión de la VII Conferencia, emitieron una orden y un Plan de Guerra (Campaña Bolivariana para la Nueva Colombia o Plan Estratégico) que las FARC pretendieron cumplir sin tomar en cuenta las transformaciones sociales del país. Durante más de 20 años, las FARC canalizaron sus esfuerzos para lograr las metas del plan, teniendo a favor los recursos del narcotráfico y la poca claridad de la sociedad y del Estado sobre la lógica de aquel. Sin embargo, este plan sufrió un duro revés con la respuesta del Estado (Plan Patriota y Plan Colombia).

\section{Relación de las FARC con la población civil}

Finalmente, respecto del eje de la relación de las FARC con la población civil, se puede destacar que han utilizado dos métodos en sus zonas de influencia: 1) inicialmente, en regiones con poca presencia estatal, las guerrillas trataron de sustituir algunas de sus funciones (ofertas de seguridad, prácticas de justicia, promoción de organización social, etc.); y 2) reclamando su presencia con obras, planes y programas.

Lo anterior pretendía reforzar la idea de que la guerrilla buscaba la inclusión de regiones en el proyecto de construcción de Estado, pero en realidad lo que se buscaba era la presencia del Estado para derrotarlo en múltiples sentidos (influyendo sobre los funcionarios locales y direccionando el gasto público hacia ciertas zonas de interés; eliminando 
la presencia de autoridades, de la Fuerza Pública o de algunas facciones partidistas; y demostrando la incapacidad del Estado para atender todas las expectativas sociales).

En realidad, tanto en uno como en otro método quedó de manifiesto que el interés estratégico de las FARC era sustituir al Estado, generando zonas de retaguardia nacional o de Frente guerrillero. Esta pretensión tiene una lógica de guerra que buscaba generar un poder dual o de prefigurar en ciertas regiones los contornos de una república fariana.

Profundizando aún más respecto a las formas de relación de las FARC con la población civil, se puede argumentar que estas fueron cambiando de acuerdo con los escenarios sociales, la situación de la agrupación armada y el proceso militar de la confrontación. En algunas ocasiones, las FARC buscaron aprovecharse de un conflicto social, por ejemplo poniéndose del lado de una de las partes del conflicto o para imponer el orden en medio de un conflicto en que se hubo desatado la violencia; en otras ocasiones, se instalaron en zonas carentes de conflictos para crearlo, y luego de aquello para estimularlo o equilibrarlo de acuerdo a sus propios intereses.

Ahora bien, las relaciones con la población civil no solo se adecuan a los escenarios sociales y regionales, sino que también responden a las lógicas de guerra. En este sentido, las FARC y otros actores armados se relacionan con los territorios atendiendo a estrategias político-militares, donde no es lo mismo una zona de retaguardia nacional o de frente guerrillero que una zona en disputa y por lo tanto, dependiendo de cual zona se trate, se puede estimular diversas acciones tales como: 1) la creación de organizaciones sociales; 2) el castigo y el suministro de justicia complementaria; 3) la defensa frente a los abusos; 4) la presión a las autoridades locales; 5) la conquista de adeptos; 6) la imposición a través de la fuerza; 7) la implantación de tributos; 8) la práctica de la extorsión; y 9) la ejecución de secuestros, entre otras acciones similares o diferenciadas entre sí. 


\section{Política contraterrorista en Colombia}

\section{La política de defensa y seguridad democrática de Álvaro Uribe}

El fracaso de las negociaciones entre las FARC y el gobierno de Andrés Pastrana y el consiguiente clima adverso contra la solución negociada del conflicto produjeron el triunfo electoral de Álvaro Uribe en 2002. Posteriormente, los logros de sus políticas de defensa y seguridad democrática llevaron a su reelección en 2006. Su propuesta de recuperación militar del territorio, combinada con la profundización de la guerra contra las guerrillas y con la desmovilización de los paramilitares (por medio de unas polémicas negociaciones), ha tenido resultados inciertos y desiguales en el territorio nacional.

Su negativa a reconocer la existencia de un conflicto interno descartó toda posibilidad de diálogos y negociaciones con la guerrilla, la cual fue considerada como un simple grupo de narcoterroristas que atacaba a un Estado plenamente legítimo. A partir de este planteamiento, su gobierno desencadenó la mayor ofensiva política, militar y jurídica contra las guerrillas en la historia del conflicto colombiano.

La estrategia de defensa y seguridad democrática implementada por Álvaro Uribe durante sus dos períodos presidenciales, se concretó en acciones jurídicas, políticas y de opinión para desatar una ofensiva militar, política y judicial contra los denominados factores de violencia (obstáculos que impedían el crecimiento económico y social del país).

Hasta la llegada de Uribe, frente a la guerra de agotamiento de las FARC, en la cual se combinaban aspectos de guerra de guerrillas con los de una guerra de posición, las fuerzas militares habían terminado siendo un actor armado que tomaba con menor frecuencia la iniciativa, y como consecuencia de ello, se había producido una peligrosa expansión de los grupos armados privados (paramilitares), los cuales con el tiempo se habían transformado en actores poseedores de fuerza a la hora de negociar una eventual paz, lo cual era claramente inconveniente. 


\section{El plan "patriota” y el plan "consolidación”}

La guerra contra las guerrillas de Álvaro Uribe, se inicia con la implementación del "Plan Patriota", también llamado "Campaña Militar J.M.", consistente en una campaña militar de las fuerzas militares y de la Policía Nacional de Colombia, implementada desde 2003 en los departamentos de Meta, Caquetá y parte de Putumayo.

La etapa inicial del Plan Patriota buscaba recuperar las zonas urbanas y las vías de comunicación contra la influencia ejercida por grupos ilegales; principalmente la guerrilla de las FARC y el ELN. La segunda etapa, denominada Plan Consolidación, comenzó el 17 de septiembre de 2004 y buscó desarticular las estructuras de las FARC en zonas rurales.

Por su parte, las FARC decidieron promover un regreso a la estrategia de guerra de guerrillas, de esta manera conservar su estructura a pesar de estar sometidos a un alto grado de presión y, de sufrir en el camino varias deserciones e incautaciones de material logístico.

Hacia 2002, según cifras del gobierno, el número de guerrilleros de las FARC solía estimarse en 18.000 hombres en tanto que a inicios de 2005, habían disminuido a unos 12.000 o 13.000 efectivos.

\section{La estrategia de contrainsurgencia de Uribe}

Robert Haddick (2010, p. 2) analiza resumidamente la estrategia de contrainsurgencia emprendida por el presidente Uribe, señalando lo siguiente:

Hace veinte años atrás, Colombia enfrentaba una crisis de seguridad, pero durante la última década, ha reducido drásticamente sus tasas de asesinatos y secuestros. Ha aplastado una serie de grupos insurgentes que luchan contra el gobierno, ha desmovilizado a los grupos paramilitares que surgieron durante el vacío de poder de la dé-

$9 \quad$ Las iniciales J.M. con que se identifica la Campaña Militar (Plan Patriota), fueron establecidas como homenaje al General Jorge Enrique Mora Rangel. El General Mora fue Comandante en Jefe del Ejército de Colombia durante el gobierno de Andrés Pastrana y Comandante en Jefe de las Fuerzas Armadas durante el gobierno de Álvaro Uribe. En el gobierno de José Santos ha sido designado como parte del equipo negociador del gobierno para los diálogos de paz con las FARC (Nota del autor). 
cada de los años noventa y ha restaurado significativamente el estado de derecho y la presencia del gobierno en todo el país. Por otra parte, durante la última década, con la ayuda de asesores estadounidenses, Colombia ha reconstruido su ejército buscando desarrollar calidad por sobre cantidad en la estructura de fuerza. Derivado de ello, el ejército de Colombia y otras fuerzas de seguridad han logrado un éxito impresionante en la lucha contra la insurgencia.

Continuando su análisis, Haddick plantea que los retos para las fuerzas de contrainsurgencia en Colombia resultaban complejos, ya que debían superar diversas situaciones que representaban ventajas significativas para los insurgentes, tales como el terreno escabroso que en Colombia ofrece a los insurgentes lugares para esconderse y que limita la movilidad terrestre de las fuerzas de contrainsurgencia, permitiendo a la guerrilla el uso de santuarios fronterizos.

Más adelante, se refiere al financiamiento del esfuerzo de la guerra insurgente mediante operaciones ligadas con el narcotráfico, y que permitió en su momento de mayor fortaleza (alrededor de 2001), que las FARC y el ELN llegaran a poner en servicio una cifra total de 21.500 combatientes, es decir alrededor de 1,9 combatientes por cada 1.000 hombres de edad militar en Colombia.

A fines de la década de los 90, Colombia se encontraba tocando fondo en materias de seguridad. El ejército colombiano se mostraba claramente ineficaz contra las fuerzas insurgentes, al punto que las FARC estaban dispuestas a enfrentar al ejército colombiano en un combate abierto convencional. Un ejemplo de aquello ocurrió en agosto de 1996, cuando una fuerza de las FARC invadió una base del ejército colombiano en el departamento Putumayo, neutralizando y capturando a más de cien soldados. En otra acción similar llevada a cabo en marzo de 1998, los combatientes de las FARC aniquilaron el Batallón de Contraguerrillas 52, considerado en ese entonces una de las unidades selectas del ejército colombiano.

Desde mediados a fines de la década de los 90, el Estado de derecho en Colombia era mínimo. En 1995, un cuarto de los municipios no contaba con una fuerza policial. La policía y los sistemas de las cortes judiciales estaban totalmente corrompidos. La tasa de asesinatos era casi 10 veces la de Estados Unidos (tasa anual de 62 asesinatos por cada 100.000 habitantes) y derivado de todo aquello, se organizaron milicias paramilitares como reacción ante la ausencia de autoridad estatal. En este débil escenario estatal, incluso el presidente Ernesto Samper, resultó cuestionado por una supuesta vinculación con los carteles de la droga. 
Sin embargo, a pesar de todo lo anterior, Colombia era poseedora de suficiente riqueza para lograr revertir la grave situación que la aquejaba, y por lo tanto, pese a que el país se encontraba resquebrajado a fines de los 90, la llegada de un gobierno central y eficaz permitió proveer el necesario apoyo que requerían sus fuerzas de seguridad para así lograr recuperar el Estado de derecho. De esta forma, las estructuras de la Fuerza Pública fueron fortalecidas y luego de ese esfuerzo inicial se logró que Estados Unidos brindase una valiosa ayuda.

En relación a aquello, Haddick (2010, p. 3) señala lo siguiente:

La naturaleza de la ayuda internacional en materia de seguridad es un tema que merece ser destacado. Ello nos lleva a resaltar la importancia de la alianza existente entre Colombia y Estados Unidos. Esta alianza es la que ha permitido, entre otras cosas, contar con una ayuda militar estadounidense circunscrita a unos 800 asesores militares que si bien tienen prohibido acompañar a las fuerzas de seguridad colombianas en las operaciones de combate, constituyen un apoyo en materias de seguridad considerado como uno de los más grandes.

Para lograr el éxito, tal como ha sido ya mencionado, el enfoque principal del Ejército colombiano dice relación con privilegiar la calidad por sobre la cantidad. Este ha sido el factor que mejor explica el éxito de Colombia y que le ha permitido mejorar notablemente a su Ejército. Esta mejora se relaciona con una reforma global que comenzó a finales del gobierno de Andrés Pastrana y cobró gran velocidad a partir del inicio de la administración del presidente Álvaro Uribe.

Las reformas que permitieron convertir al ejército colombiano en una fuerza agresiva que pudo paralizar a las FARC y al ELN, según Haddick (2010, p. 4) fueron las siguientes:

1. Nuevos líderes: En 1998, a insistencia de funcionarios estadounidenses, el presidente Pastrana reemplazó a los tres líderes principales en el ejército por generales nuevos, que habían sido entrenados en escuelas militares de Estados Unidos y quienes tenían extensa experiencia de combate en los niveles de batallón y brigada. Luego, este nuevo trío reemplazó a los comandantes subordinados que carecían de dinamismo en el campo de batalla. Al mismo tiempo, el ejército colombiano comenzó a recalcar la selección y adiestramiento de suboficiales de mejor calidad para las unidades de combate del ejército. Con ello, se puso en vigencia la 
aseveración de que es la calidad del liderazgo, y no los planes o las tácticas de la campaña, lo que facilita la obtención del éxito.

2. Reorganización: Comenzando desde la administración de Pastrana y extendiéndose hasta la administración de Uribe, Colombia reorganizó su ejército convirtiéndolo en un componente móvil y sumamente profesional. Bajo el tutelaje de los asesores de Fuerzas Especiales del Ejército de Estados Unidos, el componente profesional del ejército estableció numerosos batallones aeromóviles, de comandos, de guerra en montaña, antidrogas y de fuerzas especiales. Esas unidades mejoraron la eficacia en general del ejército al focalizarse en tareas específicas. Quizás igual de importante, Uribe se enfocó en la porción de conscripción del ejército para la defensa de las ciudades. De esta forma, se crearon más de 600 pelotones para proteger las ciudades, cada uno compuesto de alrededor de 40 soldados asignados a sus ciudades natales para ofrecer seguridad básica y recopilar inteligencia sobre las actividades de los insurgentes. Esos pelotones interceptaron el movimiento de unidades de insurgentes en el campo y dejaron libre al ejército profesional para las operaciones ofensivas. El ejército colombiano también aumentó su inversión en el apoyo logístico y en el análisis de inteligencia, actividades que igualmente fueron apoyadas por un grupo asesor estadounidense.

3. Helicópteros: El ejército y la policía de Colombia incrementaron sus respectivos inventarios de helicópteros, que no superaban más de 20 aparatos en 1998, hasta alcanzar una cifra de 255 aeronaves a fines del 2008. Para vencer el terreno montañoso y los bosques de Colombia, el ejército necesitaba movilidad aérea. Con el importante apoyo de Estados Unidos, el ejército colombiano opera actualmente la tercera flota de helicópteros UH-60 Blackhawk más grande del mundo, y gracias a esta capacidad, se ha podido concretar una ofensiva en contra de las áreas de apoyo de los insurgentes.

\section{Efectos de las operaciones de contrainsurgencia}

Como resultado de las reformas, el ejército colombiano logró causar graves daños a las FARC y al ELN. De hecho, entre 2002 y 2008, se calcula que los ataques del ejército redujeron las capacidades ofensivas de las FARC en un 70\%. Las unidades militares de las FARC, que en los 90 pudieron aplastar los batallones del ejército colombiano, para el 2008 no pudieron funcionar en unidades con tamaños más grandes que el de una es- 
cuadra. Entre el 2006 y el 2008, más de 3.000 combatientes de las FARC abandonaron la organización. Como resultado de lo anterior, muchas fuerzas insurgentes se encuentran dispersas, desorganizadas y aisladas de los líderes de alto nivel de las FARC, quienes han huido y se han exiliado en Ecuador y Venezuela.

A partir de 2008, el gobierno colombiano ha ejecutado exitosas acciones tácticas. Entre las cuales se destacan: 1) la muerte del segundo hombre de las FARC, Raúl Reyes, como resultado de la Operación Fénix ejecutada en territorio de Ecuador (año 2008); 2) el rescate de 15 rehenes en poder de las FARC mediante la exitosa Operación Jaque (año 2008); 3) la muerte del jefe militar de las FARC, el Mono Jojoy, en la Operación Sodoma donde se atacó su campamento en el departamento del Meta (año 2010); y 4) la muerte del jefe máximo de la guerrilla, Alfonso Cano, como resultado de la Operación Odiseo ejecutada en el valle del Cauca (año 2011).

Así entonces, es necesario reconocer que un aspecto gravitante en el éxito de la lucha contra las FARC-EP, se encuentra representado por el acertado accionar del presidente Álvaro Uribe, que estableció una Política de Seguridad Democrática, que resultó notoriamente exitosa. Derivada de esta política de gobierno, se creó una estrategia global que otorgó el piso necesario para sostenerla y, donde resaltaba la creación de un Comando Conjunto, la activación de un Plan de Campaña y, la estructuración de una Fuerza adecuada (Fuerza de Tarea Omega) cuyo esfuerzo principal rindió exitosos frutos.

Con este accionar, las FARC perdieron legitimidad, lo que se pudo evidenciar en una disminución de credibilidad hasta menos de 1\%. Inicialmente, las FARC ocupaban espacios abandonados por el gobierno, pero luego esos mismos lugares fueron recuperados con éxito. Ante esto, las FARC, respondieron con actos terroristas indiscriminados, tales como secuestros, asesinatos, y atentados; es decir, mediante acciones infrahumanas, las que ocasionaron que generaciones de simpatizantes de un proceso revolucionario, ahora se sintieran cada vez más lejanas de los propósitos que se pretendían alcanzar mediante métodos tan indeseables.

De esta forma, se podría argumentar que el espacio político podría estar cada vez más cerrado para las FARC, y que esto se ha logrado gracias a la actitud adoptada por la población civil. A nivel internacional, se ha evidenciado que el accionar de la guerrilla es propio de una organización terrorista y ello se ha intensificado aún más como consecuencia de los acontecimientos del 9/11. 
Las FARC se comenzaron a ver diferentes, a partir de las medidas asumidas durante el gobierno del presidente Uribe, perdiendo espacios y, siendo obligados a mostrar lo que realmente eran: una organización dispuesta a utilizar el terrorismo y el narcotráfico como instrumentos para lograr sus propósitos.

El objetivo original de las FARC era la toma del poder por la fuerza y para lograr aquello era necesario contar con el tiempo suficiente. En el caso del gobierno de Uribe, ese mismo tiempo era el mayor enemigo. Por ello, el gobierno asumió que la mejor estrategia para enfrentar esta amenaza, era estableciendo un control territorial. El propósito era recuperar la seguridad ciudadana en lugares en que imperaba el terror. Por otra parte, también optimizaron la eficacia de la Fuerza Pública por sobre la mera fuerza militar y, por lo tanto, ahora la policía, la inteligencia, la justicia y todo el resto de la estructura de los organismos del Estado, se encuentran empeñados en combatir coordinadamente con las fuerzas militares a las FARC.

Lo anterior implicó un cambio notable en el concepto tradicional de contrainsurgencia. Rápidamente puso un énfasis prioritario en la protección del ciudadano. En el antiguo concepto, se buscaba sacar del escenario al pueblo para así aislar al insurgente. En tanto, en el nuevo escenario se buscó proteger al ciudadano, hecho que termina aislando al terrorista, es decir se ha instalado la idea de que guerrilleros y población no conviven.

De esta forma, en la zona de distensión, la gente piensa en la realidad del progreso, del desarrollo, de la paz y de la educación que han ido obteniendo paulatinamente a través de un Plan de Acción Integral del gobierno y, no en la dependencia del terrorismo organizado como modo de vida. Esto ha tenido un efecto muy importante en la fuerza efectiva de las $\mathrm{FARC}^{10}$, ya que en tiempos pasados se mencionaba que éstas tenían una capacidad de recuperación de uno a tres (por cada guerrillero perdido, se lograba reclutar a tres nuevos simpatizantes) en circunstancias que ahora se enfrentan a una relación inversa (por cada nuevo reclutado pierden cuatro).

10 Según fuentes del Ejército de Colombia, los efectivos de las FARC al 2008, disminuyeron en casi un 50\% (de 16.000 efectivos originales, hoy se habla de una cifra cercana a los 8.000 guerrilleros; del porcentaje disminuido, un $40 \%$ corresponde a terroristas desmovilizados (Nota del autor). 


\section{Líneas de acción estratégica}

Las líneas de acción estratégica asumidas por el gobierno de Uribe durante su primer mandato, se pueden resumir en lo siguiente:

1. Control militar activo, en el que la fuerza pública sale de sus cuarteles abocándose a la realización de operaciones ordenadas y coordinadas centralizadamente, con un objetivo superior dispuesto al más alto nivel y, con todo el resto de las organizaciones actuando en cadena.

2. Operaciones ofensivas sostenidas, en donde se recuperan áreas en manos de la guerrilla y se permanece en el lugar, estableciendo la presencia permanente del Estado, a través de jueces, fiscales, procuradores, etc.

3. Operaciones especiales, mediante las cuales se establecen como objetivos estratégicos, tanto el rescate de secuestrados como la neutralización del liderazgo enemigo.

4. Unidad de operaciones conjuntas, conformada dependiente directamente del Comandante General, para realizar operaciones bélicas en forma coordinada.

5. Tareas prioritarias, que son establecidas para lograr la recuperación de secuestrados, la captura de enemigos, la desmovilización de guerrilleros y la eliminación física de los líderes terroristas.

Enfrentado al problema permanente de los secuestrados, el gobierno de Uribe sacó a relucir una estrategia que en su momento fue bastante cuestionada, pero que en el fondo guardaba un doble objetivo. La idea consistía en establecer cercos humanitarios, los cuales tenían la idea fundamental de estrechar la vigilancia sobre las FARC y, de paso, conminarlas a entregar a los secuestrados.

Adicionalmente $y$, ante la necesidad de recuperar a los rehenes en su poder, se orientaron grandes esfuerzos para realizar operaciones especiales de rescate de rehenes en poder de las FARC. Es decir, se otorgó una alta prioridad a la ejecución de este tipo de operaciones como parte esencial de un proceso, generado a partir de la Política de Seguridad Democrática del gobierno del Presidente Uribe. 
De aquello resulta la importancia gravitante que se otorga para la realización de este tipo de acciones y, que llevan a la aplicación de distintas tácticas y métodos destinados a su materialización.

Ahora bien, es necesario considerar que la apuesta política por oponerse al canje humanitario y privilegiar las operaciones militares de rescate, ha resultado altamente costosa en términos de legitimidad, ya que por ejemplo, y derivado de una fallida operación de rescate en abril de 2003, se produjo el asesinato del gobernador de Antioquia, Guillermo Gaviria, y del ex ministro de Defensa, Gilberto Echeverri; en tanto que en julio de 2007, también resultaron asesinados 11 de los 12 diputados de la Asamblea del Valle del Cauca, por fuego amigo entre dos frentes guerrilleros.

Sin embargo, otras acciones han tenido un rotundo éxito. Es el caso de la Operación Jaque que en julio de 2008 permitió la liberación de la ex candidata presidencial Ingrid Betancourt, tres contratistas norteamericanos y otros 11 efectivos de la policía y de las Fuerzas Armadas colombianas.

En un contexto similar, mediante la Operación Camaleón, se pudo liberar en junio de 2010 al coronel Luis Herlindo Mendieta, que permanecía como rehén de las FARC desde noviembre de 1998, con ocasión del ataque a la ciudad de Mitú.

La necesidad de obtener información útil, destinada a conocer exactamente el paradero de secuestrados en poder de las FARC, ha permitido contar con efectivos de Fuerzas Especiales con capacidades únicas en su género, con efectivos que pueden operar en la profundidad de la selva conformando equipos humanos muy reducidos (de uno a dos efectivos con capacidades individuales de autonomía de operación por hasta 15 días) y, poseedores de una notable capacidad de reconocimiento y transmisión de data en tiempo real.

Una situación similar ha ocurrido con las organizaciones de inteligencia de las diferentes fuerzas militares y policiales colombianas, las cuales son capaces de efectuar un trabajo integrado y coordinado, permitiéndoles desarrollar innovadoras técnicas y tácticas de obtención de inteligencia, entre las cuales se destacan las acciones de inteligencia humana (infiltración al interior de las propias filas de las FARC), y acciones con amplio empleo de la tecnología asociada a la inteligencia (con énfasis en el reconocimiento aéreo diurno y nocturno y, la capacidad de interceptación de comunicaciones, entre otros innovadores aspectos). 


\section{Conclusiones}

En el ámbito de la política contraterrorista en Colombia, a partir de la política de Uribe se diseñó un plan encaminado a golpear al Secretariado de las FARC que se basaba en labores de inteligencia a partir de la información producida por las masivas desmovilizaciones y capturas logradas durante su gobierno.

En este plan se hizo uso de tecnologías que analizaban y sistematizaban la información suministrada por desertores y capturados, en función de objetivos militares, para conocer mejor las vulnerabilidades del enemigo.

Este desarrollo permitió visualizar desde el 2005 una profundización del Plan Patriota y el Plan Consolidación para asediar las retaguardias militares de las FARC, especialmente en Caquetá y Meta, junto con la recuperación social del territorio que buscaba desvertebrar sus corredores estratégicos de movilidad.

A pesar de las limitaciones en los resultados iniciales, producto de la confrontación con una guerrilla combativa y militarmente fuerte, la persistencia de la ofensiva logró asestar golpes importantes y contundentes contra las FARC al abatir importantes mandos regionales e incluso a miembros del Secretariado del Estado Mayor Central.

Este fue el caso de las muertes de Raúl Reyes e Iván Ríos en marzo de 2008, junto con la muerte de su jefe histórico Manuel Marulanda Vélez, presuntamente por causas naturales, en mayo del mismo año. A estas muertes, se sumaron las de Víctor Julio Suárez, alias Jorge Briceño o Mono Jojoy, comandante militar de las FARC, en septiembre del 2010, y la de Guillermo León Sáenz, alias Alfonso Cano, máximo comandante de las FARC tras la muerte de Manuel Marulanda, en noviembre de 2011. Esta ofensiva sumió al grupo armado en una profunda crisis.

La ofensiva del Estado, no sólo replegó a las FARC a sus zonas de retaguardia, sino que las replegó hacia las fronteras nacionales, situación que puso de manifiesto la amenaza real de una propagación continental del conflicto armado hacia los países vecinos, dada la férrea posición del presidente Uribe de perseguir a los miembros del Secretariado de las FARC más allá de las fronteras nacionales.

La situación se tornó crítica entre 2008 y 2010 luego de la ruptura de relaciones diplomáticas entre Ecuador y Colombia tras el ataque contra el campamento de Raúl Re- 
yes en territorio ecuatoriano y las tensiones con Venezuela tras la denuncia del presidente Uribe sobre la presencia de miembros del Secretariado de las FARC en ese territorio, incluyendo la orden del presidente Chávez de movilizar 10 batallones a la frontera con Colombia en marzo de 2008.

En medio de la ofensiva militar del Estado, las FARC intentaron preservar la iniciativa política con su empeño en un canje humanitario de guerrilleros presos por los políticos secuestrados y los militares y policías retenidos como rehenes. Sin embargo, con el modelo coercitivo impuesto por la política de Seguridad Democrática y basado en la acción conjunta y coordinada de la Fuerza Pública, se pudo lograr una acertada capacidad para ejecutar rescates y lograr la liberación de las víctimas.

En relación a la tipología emergente del terrorismo en Colombia las FARC tienen su origen en un conflicto político y social, caracterizado por la violencia social sectaria desplegada inicialmente con ocasión de las disputas entre hacendados y campesinos, y donde tuvo una activa participación el Partido Comunista Colombiano (PCC). En este contexto, las guerrillas de las FARC no se quedaron simplemente en una violencia de respuesta o defensiva contra sus agresores sino que elaboraron un discurso político para justificar su confrontación con el Estado inspirándose en el pensamiento marxista leninista, y desarrollando tácticas y estrategias dirigidas a la toma del poder político y a la implantación de transformaciones radicales en el orden económico y social, inspiradas en las ideologías socialistas y comunistas.

La expansión de las FARC, se realizó aprovechando el abandono estatal en algunas regiones, la pobreza campesina y la difusión de los cultivos de coca. Las FARC crecieron y se expandieron en áreas apartadas geográficamente, sustituyendo al Estado en varias de sus funciones: a) resguardar ocupaciones de tierra; b) contribuir a la creación de organizaciones campesinas; c) intervenir en la solución de conflictos e imposición de penas y sanciones; d) brindar protección y seguridad frente a la delincuencia; y e) respaldar la realización de tareas colectivas en beneficio comunitario. En regiones de cultivos de coca, las FARC se ocuparon de limitar la violencia y los atropellos de narcotraficantes, imponiendo un orden mínimo al funcionamiento de la economía ilícita. A cambio, exigieron el pago de tributos sobre las operaciones comerciales, lo cual se constituyó en una de sus principales formas de sostenimiento.

Desde su creación, las FARC se han constituido como un aparato de guerra y como una organización política, combinando así la acción política con la acción militar. La faceta política implica una actividad permanente de los mandos políticos de los frentes 
guerrilleros o de las redes y comisiones políticas en las organizaciones rurales y urbanas, en tanto que la faceta militar se ha expresado en el diseño de un plan estratégico para la toma del poder, que buscaba la caída de Bogotá y de otras ciudades principales cercadas por frentes guerrilleros.

La guerra irregular desarrollada por las FARC busca afectar tanto a la Fuerza Pública como a civiles ajenos al conflicto. Las emboscadas, sabotaje e incluso el lanzamiento de explosivos artesanales y la instalación de minas antipersonal han sido ataques indiscriminados, a los cuales además se han asociado otras acciones tales como los secuestros, homicidios selectivos y reclutamientos forzados, donde ha resultado afectada la población civil.

Las FARC han buscado el reconocimiento de un estatus político por parte de diversos gobiernos colombianos. Esto se ha expresado en el otorgamiento de amnistías, indultos y beneficios penales, así como a través de conversaciones y diálogos para lograr treguas. En un determinado momento lograron el nacimiento de un movimiento político (U.P). También han logrado la realización de rondas de conversaciones entre el gobierno y la guerrilla en el exterior, con el apoyo oficial de países amigos o gobiernos extranjeros. En otras ocasiones, las FARC han conseguido intercambios humanitarios que llevaron al canje de presos por rehenes e incluso lograron una zona de distensión de la que fue retirada la Fuerza Pública y las autoridades judiciales, lo que permitió algunos ejercicios de autoridad por parte de la guerrilla. Pese a este reconocimiento de estatus político, las FARC han sido sindicadas como una de las principales organizaciones terroristas del mundo, debido a las graves violaciones a los derechos humanos en general y el derecho internacional humanitario, en particular.

Finalmente, a juicio del autor con las actuales negociaciones de paz hay más posibilidades de un acuerdo que en anteriores diálogos. Lo anterior, por cuanto las FARC ya no tienen la fortaleza de otras épocas y no cuentan con las expectativas de triunfo que ostentaban en otras negociaciones. Sin embargo, las FARC tampoco están derrotadas ni divididas. Actualmente plantean una guerra de resistencia que podría prolongarse gracias a los recursos provenientes del narcotráfico y a las alianzas con bandas criminales. En este contexto, una nueva fase del conflicto podría llevar a la aparición de nuevos actores armados, la degradación de algún sector de las actuales organizaciones guerrilleras o el reforzamiento de las nuevas bandas criminales. 


\section{Referencias}

Benegas, J. (2004). Terrorismo. Diccionario ESPASA. Madrid, España: Editorial ESPASA CALPE.

Bethell, L. (2002). Historia de América Latina. Los países andinos desde 1930. Volumen 16. Barcelona, España: Editorial Crítica.

Castellanos, J. (2013). ¿Cuánto nos cuesta la guerra? Costos del conflicto armado colombiano en la última década. Bogotá, Colombia: Editorial del Politécnico Grancolombiano.

Centro Nacional de Memoria Histórica (CNMH). (2014). Guerrilla y población civil. Trayectoria de las FARC 1949-2013. Bogotá, Colombia: Editorial Imprenta Nacional de Colombia.

Haddick, R. (2010). Colombia le puede enseñar a Afganistán (y a Estados Unidos) cómo ganar. Revista Air \& Space Power Journal. Versión en Español, Primer Trimestre. Recuperado de www.airpower.au.af.mil

Grupo de Memoria Histórica (GMH) (2013). Basta ya. Colombia: Memorias de guerra y dignidad. Bogotá, Colombia: Imprenta Nacional.

Pécaut, D. (2001). Guerra contra la sociedad. Bogotá, Colombia: Editorial Planeta.

Rangel, A. (1998). Colombia: guerra en el fin de siglo. Bogotá, Colombia: Editorial Tercer Mundo, Universidad de los Andes.

Secretaría de Estado de Estados Unidos. Foreign Terrorist Organizations (FTOs). Recuperado de http://www.state.gov/j/ct/rls/other/des/123085.htm

Unión Europea. Lista de terroristas de la UE. Recuperado de http://www.consilium.europa. $\mathrm{eu} / \mathrm{es} /$ policies/fight-against-terrorism/terrorist-list/ 